\title{
MUTUAL FUND MANAGERS: REAL OR MAKE-BELIEF PERFORMANCE
}

\author{
B. A. BUKHVALOVA \\ BI Norwegian Business School, Oslo
}

Alpha is a key indicator of mutual fund performance. It is equal to fund's risk-adjusted return in excess of a benchmark index. We find that Norwegian mutual fund investors cannot always rely on alpha based on the fund-selected benchmark index, to differentiate fund quality. Many managers appear to pick benchmarks strategically and/or adjust their portfolios in a way that maximizes alpha. Our analysis sharpens previous studies of the US data, where only a few alternative benchmarks were considered based on a coarse classification of fund investment objectives and not on actual fund-selected benchmarks. The results are economically important. Compared to the best-fit alpha, alpha relative to the benchmark that best describes fund returns, alpha of an average equity fund appears to be $0,45 \%$ higher per year. Among equity funds that "exaggerate" their alpha, the number is $1,83 \%$. We also find that the best-fit alpha, and not the fund's official alpha, has a strong statistical association with fund closing decisions. Taken together, we find these results to be strong circumstantial evidence of strategic benchmark picking.

Keywords: mutual funds, benchmarks, managerial incentives.

JEL: G11, G20, G23.

In the standard principal-agent problem, the principal gleans the skill and effort of the manager, and, in cases where the two are unverifiable, designs a compensation scheme that motivates the manager to work in the best interest of the principal. In firms with dispersed ownership, an owner may not be able to influence the compensation scheme or hiring/firing choices directly. Hence, he can only vote by feet, selling the stock and putting the downward pressure on the price. In this paper, we will consider whether Norwegian mutual fund investors can even rely on commonly available information to judge fund manager quality.

In the mutual fund industry, the standard manager compensation is a percentage of the funds under management. Investors cannot decide on the manager or the size of the fee, but by buying more shares in the fund or sell-

I thank the anonymous referee and Bogdan Stacescu for their helpful remarks and suggestions. All remaining errors are my own.

Address: BI Norwegian Business School, Oslo, NO-0442, Norway. E-mail: barbara.bukhvalova@bi.no

(C) B. A. Bukhvalova, 2017

DOI: $10.21638 / 11701 /$ spbu18.2017.202 
ing shares in the fund, they have a direct effect on the compensation received by the manager. Open-end mutual funds shrink and grow with investments being taken out of the fund (shares sold) and brought into the fund (shares bought). Additionally, the fund grows due to positive returns and shrinks with negative returns. ${ }^{1}$

[Ibert et al., 2017] find only weak sensitivity of fund managers' pay to performance, for Swedish funds. That would suggest that a Scandinavian fund manager has a relatively modest incentive for return manipulation and/ or making returns look better than they actually are. This would bias us again finding any results in Scandinavian data relative to the international practices.

How do mutual fund investors make their buying and selling decisions? The skill of the manager is uncertain and unverifiable. Investors can, however, learn something about the skill based on the past performance of the manager. Good past performance is rewarded by more investors flocking into the fund. Bad past performance is punished by outflows.

However, what is "good past performance"? The golden standard for judging past fund performance is alpha (also sometimes referred to as Jensen's alpha after the seminal [Jensen, 1968]).

The alpha, the constant term in the singlefactor, as in [Jensen, 1968], or multifactor, as in [Carhart, 1997], regression is used in the literature to judge fund performance. Positive alpha is taken to be a measure of managerial skill. Alpha higher than that of competing mutual funds then should be rewarded by investor inflows.

1 While the standard management fee in the mutual fund industry is a fixed percent of assets under management, some mutual funds have optionlike features in the fee structure. For example, the management fee may be a percentage of the value increase, with a given cap and floor for the level, as in Alfred Berg Gambak. Also, in this article we consider exclusively open-end mutual funds. Managers of closed-end funds do not get the benefit of increased pay due to inflows. Instead, they increase fees and are given new funds to manage by the relevant mutual fund families [Wu, Wermers, Zechner, 2016]).
Is the fund's alpha as obviously defined as the fund's name? Unfortunately not. Alpha estimate is sensitive not only to the choice between the single factor and the multifactor model, but also to the choice of the index. What are the obvious choices?

First, one could choose the broad market index to evaluate fund performance. According to the CAPM, all fairly priced securities should have the same linear relationship between their beta and their expected return. However, different funds have different investment objectives. The alpha estimate may be influenced by the nature of the objective. Indeed, some indices themselves have been shown to have an alpha, when regressed on the broad market return [Cremers, Petajisto, Zitzewitz, 2013]). Indices by definition are passive investments. If a mutual fund manager invests and passively holds an index that has a positive alpha against the broad market index, he does not manifest special investment abilities. Such alpha is an artifact of the index he holds. Hence, the broad market index may be an inappropriate, even if an easy choice, when evaluating mutual fund performance.

Second, one could use the benchmark index chosen and announced by the fund. ${ }^{2}$ While fund managers are fairly free in their choice of the benchmark index, they are aware that their performance will be judged against the index they choose. If the fund manager believes that his target investor would rely on alpha estimates, the manager may choose the index that will make the fund's past risk-adjusted performance seem as good as possible. Additionally,

2 In the US, all funds are required to declare an "appropriate broad-based" benchmark index to the SEC, since 1999. The SEC does not regulate the choice of benchmark. However, once a benchmark is announced, the fund has to report performance relative to this benchmark for a given period, even if the benchmark is subsequently changed by the fund management. Internationally, many funds choose to declare a benchmark. In Norway, fund-chosen benchmarks are available for most funds. Yet, there is no legal requirement to have a benchmark. The association of Norwegian mutual funds (VFF) has only non-binding recommendations for criteria to be used in choosing benchmarks by the association members. 
once he chooses an index, that choice in itself may influence his subsequent investment choices in such a way that current and future performance will seem as good as possible too. The manager's choice of the benchmark index is not as innocuous as one could have thought, but rather is a strategic choice on the part of the manager. While benchmarks can be changed over time by the management, the SEC allegedly frowns upon benchmark flip flopping [Sensoy, Kaplan, 2005]. As there is no formal benchmark reporting requirement in Norway, one would think that Norwegian fund managers would experience less pressure to keep the same benchmark. Hence, they would feel less constrained while announcing their choice of benchmark. ${ }^{3}$ That means that the alpha based on the fund-chosen benchmark may be misleading too.

Third, one could look up the fund benchmark selected by independent experts. When it comes to mutual fund analysis, Morningstar is the international leader in providing the relevant information and broad coverage. The Morningstar benchmarks may not have the drawbacks of the previous two choices, but they may still be not fund-specific enough. Indeed, the number of mutual funds domiciled in a given country is frequently greater than the number of listed stocks (this is true both in the US and Norway, for example). Comprehensive analysis of each and every fund is beyond what any mutual fund data provider could do.

Fourth, one could search for the index that fits fund's actual past performance best. This choice is the most demanding, but it has two advantages. The best-fit index is tailored to the specific fund. The index is chosen using objective criteria.

If the last approach is chosen, another question arises. What constitutes the best fit? If this question is asked of a researcher, the most likely answer is the highest coefficient of determination, $R^{2}$. In the literature and in

3 To date, there is no comprehensive time series data for benchmark choices. Bloomberg, Thomson Reuters Eikon, and Morningstar report only the most recent benchmark. practice, two other measures are often computed, the active share and the tracking error.

The active share was introduced in [Cremers, Petajisto, 2009]. It is the half sum of absolute deviations of the mutual fund portfolio weights from index portfolio weights. The active share is supposed to measure the manager's stock selection activity and was shown in [Cremers, Petajisto, 2009] to be a predictor of fund returns. The tracking error is typically measured by the volatility of the difference between fund returns and index returns. Some funds (e. g., Alfred Berg Global Deepwater Energy) may limit themselves to particular target and/or maximum levels of the measure, while others are explicitly (e.g., Alfred Berg Gambak) or implicitly noncommittal. Tracking error measures the relative systematic risk.

Both measures are sensitive to the strategic index selection by the fund manager. Consider a "closet indexer" fund that follows index $X$, but strategically reports index $Y$ as its benchmark. The fund may rank high on both measures of active fund management. Now, consider an identical fund that reports its benchmark truthfully $-X$. The fund will be reported with lower alpha ("worse" performance) and lower measures of active management. From this comparison of two identical funds, one could conclude that active management is associated with better performance. This connection is also the one established empirically in [Cremers, Petajisto, 2009].

Similarly, [Amihud, Goyenko, 2013] find that lower $R^{2}$ is associated with better performance. They associate this result with greater selectivity. The approach in [Amihud, Goyenko, 2013] is preferable to the active share measure of [Cremers, Petajisto, 2009], in the sense that it does not require information on portfolio composition. In the US, mutual funds are required to report their holdings to the SEC at the quarterly frequency. In Norway, and in many other countries, there is no requirement for detailed public reporting. So, only $R^{2}$ and the tracking error can be computed. Both are vulnerable to strategic selection of reported index. 
We suggest searching for the best-fit benchmark using $R^{2}$, as the first step in analyzing how actively managed a given fund is. Only then, should one compute the active share and the tracking error and/or analyze relative $R^{2}$. In this paper, however, we have nothing to say about managerial ability and active management and focus purely on the evidence of strategic index selection.

Suppose we analyze a fund and find that its $R^{2}$ against the fund-selected benchmark index is low. This could be explained away by active management. Suppose this fund's returns have a higher $R^{2}$, when regressed on an alternative index. There are two potential explanations. First, it could be a fluke, an accidental outcome of mechanical matching between funds and indices. This undesirable outcome could be addressed by performing analysis for different time periods. Second, it could be a "mistake" made by the manager. If the mistake is an "honest mistake" and/or if we have encountered a statistical "fluke", we expect to see no pattern of connection between alphas computed for fund-selected benchmarks ("fund-selected alphas") versus alphas computed for best-fit indices ("bestfit alphas").

We find that the best-fit alphas are systematically lower than fund-selected alphas. The previous research on benchmark index selection by funds was ignited by results in [Sensoy, 2009]. He found nearly one-third of active US domestic equity funds misrepresented their investment style (along the size and value/growth dimensions). He attributed the result to unsophistication of investors. [Elton, Gruber, Blake, 2014] show that wealthy and institutional investors investing in separately managed accounts and collective investment trusts are susceptible to the same influences.

These studies considered only US (domestic) equity funds. Funds that held both equity and fixed income instruments as well as funds that held internatinal equity were dropped. As a result, the universe of considered indices was quite small. [Sensoy, 2009] considers 12, and [Elton, Gruber, Blake, 2014] consider 22 benchmark indices. [Angelidis,
Giamouridis, Tessaromatis, 2013] consider a horse race of 9 indices at a time.

Our study covers all funds domiciled in Norway. Norwegian market is interesting to study in this context for several reasons. First, it is a developed economy with wealthy and relatively well educated population. Second, just like in most other counties, Norwegian mutual funds can invest at their discretion as long as they stay within the confines they impose on themselves in the prospectus. Third, the main regulatory restriction that applies to Norwegian funds is the diversification requirement. Funds cannot invest more than $10 \%$ of their assets into securities of the same issuer. If a fund invests more than $5 \%$ of its assets into securities of an issuer, such investments combined cannot add up to more than $40 \%$ of the fund's assets. This means that Norwegian funds may not be able to passively follow some indices, if indices have a small number of constituents and/or constituents with weights of more than $10 \%$. Fourth, Norway has quite lax regulation of mutual fund benchmark selection by fund managers. Finally, Norway always ranks at the top of the international trust index. We can verify whether trusting Norwegian fund managers is less precarious than trusting US fund managers.

We make several contributions to the literature. First, we study benchmark selection across all types of open-end mutual funds: equity, fixed income, and mixed. Second, we perform comprehensive analysis against a vast number of potential benchmarks. Third, we supplement comparison of fund-selected and best-fit benchmarks with addition of Morningstar assigned benchmarks. Finally, we look for evidence of strategic index choice in a developed market with less stringent regulation of index selection than the US.

The paper is organized as follows. Section I describes the data. Section II presents empirical results. Finally, Section III concludes.

\section{Data}

Our analysis covers the universe of Norwegian-domiciled open-end mutual funds, dur- 
ing the period between January 1980 and March 2015, collected from the Morningstar database. The data includes all funds that were active at any point during the period. All return data is at the monthly frequency.

The universe of considered benchmarks is based on at least one fund in Sweden, Denmark or Norway declaring it or Morningstar choosing it for at least one of these funds. One easy way for a fund manager to make the fund look its best is to choose the net return version of the index as the benchmark. Net return indices are computed under the assumption that the investor (in this case, the fund) pays all withholding taxes on dividends. In practice, in most cases, mutual funds are not subject to double taxation. The capital gains tax is assessed once and is paid by the mutual fund investor. We choose not to drop these indices from consideration, even though they bias our results against finding any evidence of strategic benchmark picking. We have 1323 benchmarks with non-missing returns to include in the horse race of benchmark alternatives. Some benchmarks are pure indices, e.g. MSCI World Index. Other benchmarks are weighted sums of indices, e.g. 50\% MSCI World Index + 50\% 1-month LIBOR. We consider both types of benchmarks equally, but we do not consider alternative weightings for benchmark components. Mutual fund benchmarks are available only cross-sectionally.

In order to compute excess returns, we need to collect risk free rates. Morningstar selects what it deems to be appropriate fund-specific risk-free rates. The choice is apparently based on the primary target market of the fund. For example, some funds are assigned the 3-month US T-bill rate. As all regressions are for monthly returns, we feel it is inappropriate to use risk-free rates with other maturities. Furthermore, as all funds are Norwegian and most investors are Norwegian, we believe the most appropriate rate is the 1-month NIBOR. However, for the sake of completeness, we perform analysis first with the NIBOR and then again with the Morningstar-selected rates.

There are three types of return series computed by the Morningstar, net, total, and gross returns. Net returns capture evolution of fund share prices. Total returns combine net returns with any returns from reinvested dividends. Gross returns combine total returns with fund expenses. Gross returns are supposed to most closely mimic fund's portfolio returns. We, thus, rely on the gross returns data in our search for a best-fit index. We then use the best-fit index to compute alpha based on the fund's total returns. It is the total returns alpha that will be salient, as it represents investor returns.

We require that the fund-chosen benchmark is available in Morningstar and its return series is non-missing. We drop virtual share classes of mutual funds. We require that at least 36 months of returns (gross and total) are available. This leaves us with 367 funds, if we use the NIBOR, and 343 funds, if we use the Morningstar-selected risk-free rate.

\section{Results}

The first step in the analysis is to run a timeseries regression for each fund-index pair,

$$
R_{f, t}-R_{R F, t}=\alpha_{f, i}+\beta_{f, i}\left(R_{i, t}-R_{R F, t}\right)+\varepsilon_{f, i, t},
$$

where $R_{f, t}$ is the gross return of fund $f$ in period $t, R_{R F, t}$ is the risk-free rate, and $R_{i, t}$ is the return of index $i$ in period $t$. So, for each fund, we run 1323 regressions (the fund-selected index, the Morningstar-selected index and all other alternatives). As we consider funds that invest in different markets, no single set of factors would be appropriate for the analysis. We are naturally constrained to the single-factor model of [Jensen, 1968].

Then, we compare regression results and, for each fund, identify the index that corresponds to the highest adjusted $R^{2}$. This index may be the fund-selected index, the Morningstar-selected index or any other index.

Most common best-fit indices are reported in table 1. Fund-selected benchmark is always in top 5, but, for equity funds, it is not the top choice. The most basic benchmark, the Mutual Fund Benchmark maintained by the Oslo Stock Exchange, is the most likely best fit. Interestingly, 
Most common best-fit indices

\begin{tabular}{|c|c|c|c|}
\hline Rank & All & Equity & Fixed Income \\
\hline \multicolumn{4}{|c|}{ Panel A. All periods, NIBOR Risk-free rate } \\
\hline 1 & Fund Prospectus: 57 & OSEFX Mutual Fund: 33 & Fund Prospectus: 37 \\
\hline 2 & OSEFX Mutual Fund: 34 & Fund Prospectus: 20 & BofAML NOK 1M-LIBOR CM: 24 \\
\hline 3 & BofAML NOK 1M-LIBOR CM: 24 & MSCI ACWI NR: 7 & OSE 5-year T-bond: 8 \\
\hline 4 & Morningstar Selected: 9 & Morningstar Selected: 6 & NYSE 7-10-year T-Bond TR: 6 \\
\hline 5 & OSE 5-year T-bond: 8 & FTSE All World NR: 5 & Barclays Build America Bonds TR: 4 \\
\hline \multicolumn{4}{|c|}{ Panel B. All periods, Morningstar Risk-free rate } \\
\hline 1 & Fund Prospectus: 50 & OSEFX Mutual Fund: 33 & Fund Prospectus: 31 \\
\hline 2 & OSEFX Mutual Fund: 34 & Fund Prospectus: 19 & NYSE 7-10-year T-Bond TR: 14 \\
\hline 3 & MSCI ACWI FM NR: 19 & MSCI ACWI FM NR: 19 & S\&P 500 VIX Short Term Futures TR: 12 \\
\hline 4 & $\begin{array}{l}\text { NYSE 7-10 Yr Treasury Bond TR: } \\
14\end{array}$ & $\begin{array}{l}\text { MSCI ACWI ex-Canada } \\
\text { Index: } 9\end{array}$ & OSE OSE 5-year T-bond: 11 \\
\hline 5 & $\begin{array}{l}\text { S\&P } 500 \text { VIX Short Term Futures } \\
\text { TR: } 12\end{array}$ & MSCI EFM NR: 7 & $\begin{array}{l}\text { Morningstar EM Corp-Bond TR EUR } \\
\text { Hedged: } 7\end{array}$ \\
\hline
\end{tabular}

N ot e: "Fixed Income" funds in this table include funds classified by Morningstar as "Fixed income" and as "Money market".

the Morningstar-selected benchmark is not in top 5, when the Morningstar-selected riskfree rate is used to compute excess returns.

Finally, we rerun the same regression, but now using total fund returns on the left-hand side. It is sufficient to regress mutual fund returns only on the fund-selected index, the Morningstar-selected index, and the best-fit index identified in the previous step.

The summary of regression results is in table 2. We can immediately see that funds are much more likely to have selected a benchmark that makes their alpha look better. Morningstar is far from being overly aggressive in the benchmark selection too. Morningstar is quite likely to agree with the manager on benchmark selection. One may argue that looking at the entire history since 1980 may be a too broad of a look. The performance measures reported by Morningstar are by default based on three years of observations. We repeat the entire exercise using only the most recent three years of data for each fund. ${ }^{4}$ The results are

4 If a fund was closed before the end of the sample period, we go back until we collect three years of non-missing observations. not as clear-cut as the longer term regression results. First thing to note is that while fund managers are still a bit more likely to flatter their own performance, Morningstar is, if anything, overly strict. As a result, over a shorter performance horizon, fundselected benchmarks produce higher alphas than Morningstar-selected benchmarks.

It may seem that fixed-income fund managers are the most honest, in particular, if one focuses on Panel B of table 2. It is hard to make this comparison, however, as there are fewer fixed-income benchmarks than equity benchmarks to credibly choose from. Unlike equity indices, many fixed-income indices do not have net return counterparts available. Additionally, the last three years coincide with the period of unprecedentedly low interest rates. Fixed income funds have lived through very difficult times.

It is informative to view results in table 2 together with results in table 3 . The latter shows average consequences of different benchmark choices. The numbers in table 3 are annualized alphas, in percentage points. For example, an average equity fund has a best-fit alpha of $0,45 \%$ lower than its fundselected alpha. An average equity fund that

PЖM 15 (2): 163-172 (2017) 
Table 2

Manager, Morningstar, and best-fit alphas

\begin{tabular}{|c|c|c|c|c|c|c|c|c|c|}
\hline \multirow{2}{*}{ Fund Type } & \multicolumn{3}{|c|}{$\alpha_{F}$} & \multicolumn{3}{|c|}{$\alpha_{M}$} & \multicolumn{3}{|c|}{$\alpha_{F}$} \\
\hline & $>\alpha^{*}$ & $<\alpha^{*}$ & $=\alpha^{*}$ & $>\alpha^{*}$ & $<\alpha^{*}$ & $=\alpha^{*}$ & $>\alpha_{M}$ & $<\alpha_{M}$ & $=\alpha_{M}$ \\
\hline \multicolumn{10}{|c|}{ Panel A. All periods, NIBOR Risk-free rate } \\
\hline All & 166 & 105 & 57 & 178 & 98 & 44 & 74 & 95 & 152 \\
\hline Equity & 108 & 73 & 20 & 120 & 68 & 12 & 58 & 75 & 67 \\
\hline Fixed income & 52 & 32 & 37 & 56 & 29 & 32 & 13 & 20 & 85 \\
\hline \multicolumn{10}{|c|}{ Panel B. Most recent 3 Years, NIBOR Risk-free rate } \\
\hline All & 146 & 131 & 52 & 124 & 147 & 50 & 106 & 61 & 154 \\
\hline Equity & 99 & 75 & 27 & 81 & 90 & 29 & 89 & 42 & 69 \\
\hline Fixed income & 43 & 54 & 25 & 41 & 56 & 21 & 14 & 19 & 85 \\
\hline \multicolumn{10}{|c|}{ Panel C. All periods, Morningstar Risk-free rate } \\
\hline All & 155 & 122 & 50 & 166 & 120 & 34 & 74 & 95 & 152 \\
\hline Equity & 103 & 79 & 19 & 114 & 77 & 9 & 59 & 74 & 67 \\
\hline Fixed income & 47 & 43 & 31 & 50 & 42 & 25 & 12 & 21 & 85 \\
\hline
\end{tabular}

Note: $\alpha_{F}$ is the intercept from the regression with fund-selected benchmark on the right-hand side. $\alpha_{M}$ is based on the Morningstar-selected benchmark. $\alpha^{*}$ is the best-fit alpha. "Fixed income" funds include funds classified by Morningstar as "Fixed income" and as "Money market".

Table 3

\section{Differences in alphas}

\begin{tabular}{l|c|c|c|c|c|c}
\hline \multirow{2}{*}{ Fund type } & $\boldsymbol{E}\left(\left|\alpha_{F}-\alpha^{*}\right|\right)$ & $\boldsymbol{E}\left(\left|\alpha_{M}-\alpha^{*}\right|\right)$ & \multicolumn{2}{c}{$\boldsymbol{E}\left(\left|\alpha_{F}-\alpha^{M}\right|\right)$} \\
\cline { 2 - 7 } & $\alpha_{F}>\alpha^{*}$ & $\alpha_{F}<\alpha^{*}$ & $\alpha_{M}>\alpha^{*}$ & $\alpha_{M}<\alpha^{*}$ & $\alpha_{F}>\alpha^{M}$ & $\alpha_{F}<\alpha^{M}$ \\
\hline \multicolumn{7}{c}{ Panel A. All periods, NIBOR risk-free rate } \\
\hline All & 1,559 & 1,482 & 1,515 & 1,529 & 1,144 & 1,087 \\
\hline Equity & 1,826 & 1,591 & 1,927 & 1,617 & 1,073 & 1,288 \\
\hline Fixed income & 0,754 & 1,234 & 0,614 & 1,252 & 0,991 & 0,336 \\
\hline \multicolumn{7}{c}{ Panel B. Most recent 3 years, NIBOR risk-free rate } \\
\hline All & 2,503 & 2,567 & 2,501 & 2,205 & 1,231 & 1,231 \\
\hline Equity & 2,883 & 3,827 & 3,308 & 3,252 & 1,225 & 1,664 \\
\hline Fixed income & 1,451 & 0,901 & 0,907 & 0,540 & 1,108 & 0,272 \\
\hline \multicolumn{7}{|c|}{ Panel C. All periods, Morningstar risk-free rate } \\
\hline All & 1,505 & 1,415 & 1,498 & 1,340 & 1,222 & 1,038 \\
\hline Equity & 1,920 & 1,558 & 1,995 & 1,608 & 1,168 & 1,244 \\
\hline Fixed income & 0,500 & 1,151 & 0,343 & 0,797 & 1,023 & 0,313 \\
\hline
\end{tabular}

Note: The numbers in the table are in terms of annual percentage points. They are averages of alpha differences for different subsets. $\alpha_{F}$ is the intercept from the regression with fund-manager-selected benchmark on the right-hand side. $\alpha_{M}$ is based on the Morningstar-selected benchmark. $\alpha^{*}$ is the best-fit alpha. "Fixed income" funds in this table include funds classified by Morningstar as "Fixed income" and as "Money market".

picked a benchmark with a higher alpha than the best-fit alpha overstates the risk-adjusted performance by $1,83 \%$.

Panel B of table 3 makes it clear that regressions with a 3-year horizon are notori- ously noisy, with much greater discrepancies between what different alphas suggest. While funds, in general, are still more likely to choose a more favorable alpha than the best-fit alpha (Panel B, table 2), large alpha 
Table 4

Life and death deicisions: Different alphas

\begin{tabular}{|c|c|c|c|c|c|}
\hline & $\begin{array}{c}\text { (1) } \\
\text { Died }\end{array}$ & $\begin{array}{c}(2) \\
\text { Died }\end{array}$ & $\begin{array}{c}\text { (3) } \\
\text { Died }\end{array}$ & $\begin{array}{c}\text { (4) } \\
\text { Died }\end{array}$ & $\begin{array}{c}(5) \\
\text { Lived }\end{array}$ \\
\hline Intercept & $-0,4019 * * *$ & $-0,1645$ & $-0,8426$ & 5,5441 & $33,5842^{* * *}$ \\
\hline$\overline{\alpha_{F}}$ & $-0,2888$ & $-0,2592$ & $2,8697^{*}$ & $-8,2480 * * *$ & 0,7815 \\
\hline$\alpha^{*}$ & $-1,5413^{* * *}$ & $-1,1553^{* *}$ & $-4,7137^{* * *}$ & $5,3988^{* *}$ & $2,4718^{* *}$ \\
\hline$\overline{\alpha_{M}}$ & $-0,8646$ & $-1,1865$ & $-1,4640$ & 0,2452 & 2,1134 \\
\hline Origination $F E$ & $\mathrm{NO}$ & YES & YES & YES & YES \\
\hline $\operatorname{adj} R^{2}$ & & & & & 0,8235 \\
\hline$D f$ & 316 & 287 & 133 & 128 & 287 \\
\hline
\end{tabular}

Note: (1)-(4) are probit regressions. The left-hand-side variable is one if the fund "dies" during the sample period and zero otherwise. (5) is a regular OLS regression. The left-hand-side variable is the age of fund (either at the time of closing or in the end of the time series). Regressions (1), (2), and (5) are for all funds. Regression (3) is for funds that chose a benchmark with a higher alpha than the best-fit alpha. Regression (4) is for funds that chose a benchmark with a lower alpha than the best-fit alpha. $\alpha_{F}$ is the intercept from the regression with fundselected benchmark on the right-hand side. $\alpha_{M}$ is based on the Morningstar-selected benchmark. $\alpha^{*}$ is the best-fit alpha. "Origination $F E$ " is the year fixed effect for the year of fund's origination.

$* * *$ indicates significance at $1 \%, * *-$ at $5 \%$, and ${ }^{*}-$ at $10 \%$.

estimate outliers make any average inferences challenging (Panel $\mathrm{B}$, table 3 ).

So far, we have looked at the regression results that used the 1-month NIBOR to compute excess returns. Morningstar publishes fund-specific risk-free rate choices. We repeat our analysis using the Morningstar risk-free rates instead. The results are in Panels $\mathrm{C}$ of table 2 and table 3 . The general message is still the same. An average equity fund overstated its alpha by $0,41 \%$ relative to the bestfit alpha. We should be a little careful with results of Panel $\mathrm{C}$, since the Morningstar risk-free rates have missing values, while the 1-month NIBOR has none. Hence, the number of observations is reduced making all estimates less reliable.

What if despite asymmetric nature of alpha errors the fund management truly believes in their chosen benchmarks? Then, the management should not make any decisions that appear to be driven by the best-fit alpha. A very important decision made by fund families about individual funds is on fund closures. Fund families routinely close non-performing funds and open new funds. Funds that stay open longer are those that perform best. If the fund management believes in their benchmark choice, their decision whether to close a fund or keep it open should be unrelated to the best-fit alpha. It should be based on the fund-selected alpha.

In order to study association between fund alphas and fund closing decisions, we first run several probit regressions. The results are in columns (1)-(4) of table 4. The left-hand-side variable is one if the fund "dies" during the sample period and zero otherwise. The first specification is the easiest and has only three alphas on the right-hand side, the alpha of the fund-selected benchmark, the best-fit alpha, and the alpha of the Morningstar-selected benchmark. While all alphas have negative coefficients, as expected, only the best-fit alpha is statistically significant. The decision to close is not independent of the age of the fund. [Lunde et al., 1999] show that the fund survival likelihood is not independent of its age. We add fixed effects for the years of fund origination in the data. Best-fit alpha remains negative and significant. We then split the sample into the funds that make their alpha look too good (regression (3)) and the funds that make their alpha look to low (regression (4)). Now, the fund-selected alpha, $\alpha_{F}$, becomes significant. Having an overly inflated $\alpha_{F}$ is, actually, associated with a higher likelihood of closure, while having an unduly modest $\alpha_{F}$ is associated with a lower likelihood of

PЖM 15 (2): 163-172 (2017) 
closure. In each case, the effect of the best-fit alpha has a counterbalancing sign. Finally, we analyze association between lifetime alphas and fund longevity. Regression (5) is a standard OLS model with the fund age on the left-hand-side (either at the time of closing or in the end of the time series). We can see that the only significant slope variable is the best-fit alpha and it is positive. Longer-lived funds tend to have higher best-fit alphas.

We struggle to come up with a rational explanation for a strong statistical association between fund closing decisions and the best-fit alpha. Unless we accept our results as convincing circumstantial evidence of strategic benchmark selection, one would expect no association. If the fund management knows its alpha to be a less accurate measure of performance than the available alternatives, they will ignore it and make decisions based on a better measure. Interestingly, the Morningstar-selected alpha is insignificant in all considered specifications. Even though Morningstar benchmark and alpha are quite salient in the market, it also appears to be less important than the best-fit alpha.

\section{Conclusion}

Fund managers know that at least some investors will choose among mutual funds based on their alphas. Fund manager salary is positively affected by investors buying new shares in the fund. This gives the fund manager a personal incentive to make alpha

\section{REFERENCES}

Amihud Y., Goyenko R. 2013. Mutual fund's $R^{2}$ as predictor of performance. Review of Financial Studies 26 (3): 667-694.

Angelidis T., Giamouridis D., Tessaromatis N. 2013. Revisiting mutual fund performance evaluation. Journal of Banking and Finance 37 (5): 1759-1776.

Carhart M. M. 1997. On persistence in mutual fund returns. Journal of Finance 52 (1): 57-82. seem as high as possible. We found that the fund-selected benchmarks give systematically wrong impression about funds' performance records. The benchmarks make funds look unrealistically good, on average, especially over longer horizons.

Management of mutual fund families routinely reviews performance of individual funds. Funds that are deemed to have insufficient performance are closed. New funds are opened. The management also needs a criterion to judge performance. It appears that the criterion used by management is not based on the fund-selected benchmark, but rather on (or something closer to) the bestfit benchmark. This appears to suggest that the inappropriateness of the fund-selected benchmark is known and acknowledged by the fund family management.

We have intentionally kept away from the topic of fund performance. It is beyond the scope of the paper to answer which funds outperform and which underperform. The literature on the topic is vast. We chose to take a step back and to analyze what can and cannot be used to measure fund performance.

The best-fit benchmark is identified purely mechanically. This procedural simplicity is both a blessing and a curse. On the plus side, one can quickly analyze many funds. At the same time, the best-fit benchmark match may be meaningless and purely accidental, in some cases. We have shown that it is meaningful on average. Assessment of potential errors is a topic for future research.
Cremers M., Petajisto A. 2009. How active is your fund manager? A new measure that predicts performance. Review of Financial Studies 22 (9): 3329-3365.

Cremers M., Petajisto A., Zitzewitz E. 2013. Should benchmark indices have alpha? Revisiting performance evaluation. Critical Finance Review 2 (1): 1-48.

Elton E.J., Gruber M.J., Blake C.R. 2014. The performance of separate accounts and 
collective investment trusts. Review of Finance 18 (5): 1717-1742.

Ibert M., Kaniel R., Van Nieuwerburgh S., Vestman R. 2017. Are Mutual Fund Managers Paid For Investment Skill? Working Paper No. 23373. NBER Working Paper Series.

Jensen M.C. 1968. The performance of mutual funds in the period 1945-1964. Journal of Finance 23 (2): 389-416.

Lunde A., Timmermann A., Blake D. 1999. The hazards of mutual fund underperformance: A Cox regression analysis. Journal of Empirical Finance 6 (2): 121-152.
Sensoy B.A. 2009. Performance evaluation and self-designated benchmark indexes in the mutual fund industry. Journal of $\mathrm{Fi}$ nancial Economics 92 (1): 25-39.

Sensoy B.A., Kaplan S. N. 2005. Do Mutual Funds Time Their Benchmarks? Working paper. University of Chicago Graduate School of Business.

Wu Y., Wermers R., Zechner J. 2016. Managerial rents vs. shareholder value in delegated portfolio management: The case of closed-end funds. Review of Financial Studies 29 (12): 3428-3470.

DOI: $10.21638 / 11701 /$ spbu18.2017.202

Initial Submission: May 11, 2017

Final Version Accepted: June 20, 2017

Поведение ленеджеров паевъх фондов: действительная или притворная доходность

\author{
В.А.Бухвалова \\ Норвежская школа бизнеса, ВI, Осло
}

Альфа является основным показателем качества управления фондом, показывающим превышение доходности фонда над доходностью эталонного индекса с учетом риска. Мы выяснили, что инвесторы, вкладывающие в норвежские паевые фонды, не всегда могут осуществить дифференциацию качества фондов на основе данных о величине альфа, рассчитанной с помощью выбранного фондом индекса. Представляется, что многие менеджеры на основе стратегических соображений выбирают индексы и/или формируют свои портфели так, чтобы максимизировать наблюдаемую величину альфа. Приводимый в статье анализ уточняет предыдущие исследования, основанные на американских данных, где рассматривались лишь немногие альтернативные индексы, связанные с упрощенной классификацией инвестиционных задач фонда, а не индексы, реально используемые каждым фондом. Полученные нами результаты обладают экономической значимостью. По сравнению с оптимальной величиной альфа, которая соответствует индексу, наилучшим образом описывающему доходность фонда, для фондов акций средняя годовая величина официальной альфа на $0,45 \%$ выше. У фондов акций, которые «преувеличивают» свою альфа, эта величина составляет $1,83 \%$. Обнаружено, что именно оптимальная альфа, а не официальная альфа фонда имеет сильную статистическую связь с решением фонда о его закрытии. В совокупности полученные результаты представляют веское косвенное доказательство наличия у менеджеров стратегических соображений при выборе индекса.

Ключевые слова: паевые инвестиционные фонды, бенчмарки, мотивация менеджеров.

JEL: G11, G20, G23.

DOI: $10.21638 / 11701 /$ spbu18.2017.202

Статья поступила в редакцию

11 мая 2017 г.

Принята к публикации

20 июня 2017 г.

PЖM 15 (2): 163-172 (2017) 